\title{
Comparison between Expert Systems, Machine Learning, and Big Data: An Overview
}

\author{
Maad M. Mijwil ${ }^{1}$, Dhamyaa Salim Mutar ${ }^{2}$, Youssef filali $^{3},{\text { Karan } \text { Aggarwal }^{4}, \text { and Humam Al-Shahwani }}^{5}$ \\ ${ }^{1}$ Computer Techniques Engineering Department, Baghdad College of Economic Sciences University \\ Baghdad, Iraq \\ Email: mr.maad.alnaimiy [AT] baghdadcollege.edu.iq
}

${ }^{2}$ Business Administration Department, Baghdad College of Economic Sciences University

Baghdad, Iraq

Email: dhamyaa.salim [AT] baghdadcollege.edu.iq

\author{
${ }^{3}$ Department of Computer science, Faculty of Sciences Dhar-Mahraz, University of Sidi Mohamed Ben Abdellah \\ Fez, Morocco \\ Email: Filaliucf [AT] gmail.com \\ ${ }^{4}$ Electronics and Communication Engineering Department, Maharishi Markandeshwar (Deemed to be University) \\ Mullana, Ambala, India \\ karan.170987 [AT] gmail.com \\ ${ }^{5}$ Computer Science Department, College of Science, University of Baghdad \\ Baghdad, Iraq \\ Email: Homam.Emad [AT] Sc.uobaghdad.edu.iq
}

\begin{abstract}
Today, the science of artificial intelligence has become one of the most important sciences in creating intelligent computer programs that simulate the human mind. The goal of artificial intelligence in the medical field is to assist doctors and health care workers in diagnosing diseases and clinical treatment, reducing the rate of medical error, and saving lives of citizens. The main and widely used technologies are expert systems, machine learning and big data. In the article, a brief overview of the three mentioned techniques will be provided to make it easier for readers to understand these techniques and their importance.
\end{abstract}

Keywords- Artificial Intelligence, Expert Systems, Machine learning, Big Data, COVID-19.

\section{INTRODUCTION}

Artificial intelligence [1-3] is a computer-based system that simulates and understands human users' thoughts and behaviours [4]. In the modern era, many studies are being conducted on the similarity between the mind of the computer and the mind of humans and how to transform the mind of a human being into a machine to be employed in many fields [5].In other words, the science of artificial intelligence tries to make an intelligent system and expand the fields of science and scientific research to make the machine work in the place of the human in making accurate decisions [6][7]. Moreover, it has become essential to expand and develop artificial intelligence and convey its ideas to all societies and how to benefit from it in any field. One of the most influential parts of artificial intelligence is machine learning [8], which continues to shape learning systems for devices. In addition, artificial intelligence endeavours to solve a problem intuitively within its mathematical and logical techniques [9][10]. For instance, artificial intelligence with learning technology allows the user to understand to play an online game on their own, realise the error the technology has made in the system every time a player loses the game, and move forward without repeating it in the next round, allowing this to solve the game entirely. The point is that computers and artificial intelligence have a place in human life to develop the skill of thinking and achieving daily tasks. Artificial intelligence is characterised by not repeating its mistakes in the following situation by recognising its mistakes like humans [11][12]. Still, it differs in terms of interactive features and access to the required solution. Fortunately, artificial intelligence techniques have human-like reactions to every situation [13].

The main contribution of this article is to provide a short and general overview of the three techniques (expert systems, machine learning and bigdata) so that readers can understand these techniques and how they are utilised in research work using these techniques. In Section 2, the three techniques will be discussed, and Section 3 concludes the article. 


\section{THE TECHNIQUES}

\subsection{Expert systems}

Since time immemorial, humanity has attempted to understand the universe and nature. However, people continue to discover new intelligent and effortless ways to make their lives easier to do their jobs. Artificial intelligenceis one of the critical concepts increasingly employed in various fields today, appears due to the increasing need of humans for its technologies [14][15]. Expert System is a sub-branch of artificial intelligence [16][17]. Also, it is a computer system that utilises the ability and skills of one or more professionals to solve a specific concern [18][19]. Moreover, these systems are consulting computer programs that seek to simulate the mind of experts in solving some specialised problems related to the field they are dealing with, which always leads to information-based operations [20-22].In short, they are computer programs that can solve any concern in a particular field in the same way that experts do. In fact, the origin of expert systems is the method implemented to automatically carry out the process of processing the information of human intelligence by the machine [23]. To do this, the knowledge and experience of experts must be transferred to the computer and kept by the computer. Thus, these systems utilise the information in the knowledge base to solve the concern that is handled with a structure similar to the human decision-making process.Expert systems also supply information about the 'how' and 'why' they came to the judgment they obtained while solving the concern. In addition, expert systems take a hierarchical approach to problem-solving [24][25]. These systems are characterised by combining a minimum level of knowledge and experience from different decisions. Thus, combining information from different decisions expands the expertise available to solve the concern under thinking. Expert systems are first designed as a subbranch of artificial intelligence in the 1960s for use in disease diagnosis problems in medicine in order to deal with complex concerns [26][27]. Today, expert systems are applied in diagnosing, monitoring, analysing, counselling, planning, explaining, learning, narrating, giving ideas and many more. In addition, in the absence of experts, it is aimed at quickly and accurately solving problems by increasing the efficiency of work and the quality of decisions made. The main components of expert systems are: knowledge base, user interface and inference engine.

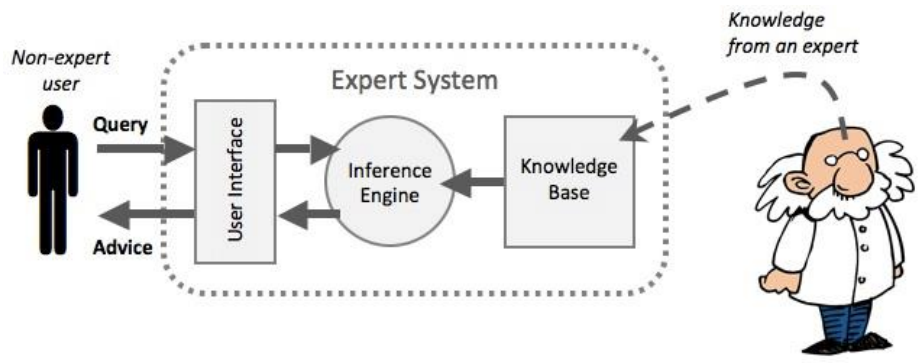

Figure 1. General structure of expert systems [downloaded from Google].

From Figure 1, it is exhibited that expert systems can describe and keep information in a particular way and form. The knowledge base contains information that is already known. In order for expert systems to transfer the acquired experience to the computer, the information provided must be written in the required format. At the same time, a user interface consists of a database and a database of rules. It takes advantage of the rules in the rule base to present expert knowledge to the user using the available data. The third part is the inference engine is the station in which the appropriate answers to the question posed by the user are generated employing the information in the knowledge base. Indeed, expert systems have the adequate ability to communicate closely with the user and only receive information about the actual situation from the user. This mechanism is accomplished through the user interface. In addition, the information is processed in the inference engine and the extracted results are transmitted to the user through the user interface. Moreover, expert systems can also have self-development features if they are correctly designed.

\subsection{Machine learning}

Machine learning is a set of techniques designed to solve a specific issue according to the evidence got from the problem environment [28-30]. By glancing at a large collection of articles, machine learning can be known as a system that allows the machine to work better again, either when the same task is repeated or in a different mission in another field.Some methods and algorithms are capable of predicting, estimating, and some of them are capable of classification [31-34]. In other words, these methods and algorithms help solve problems and make decisions. In addition, prediction is noteworthy in machine learning [35]. Also, these techniques have the potential to assist experts in achieving data analysis, especially in the medical and many other fields.Some think that machine learning and statistics work on the same principle [36], but this is incorrect. Machine learning is concerned with how accurate the prediction of training data is, while statistics are concerned with both correct prediction and how models and methods are interpreted, as well as the quality of these models and methods. Machine learning and statistics are not against each other, but they are complementary fields. 
Types of Machine Learning
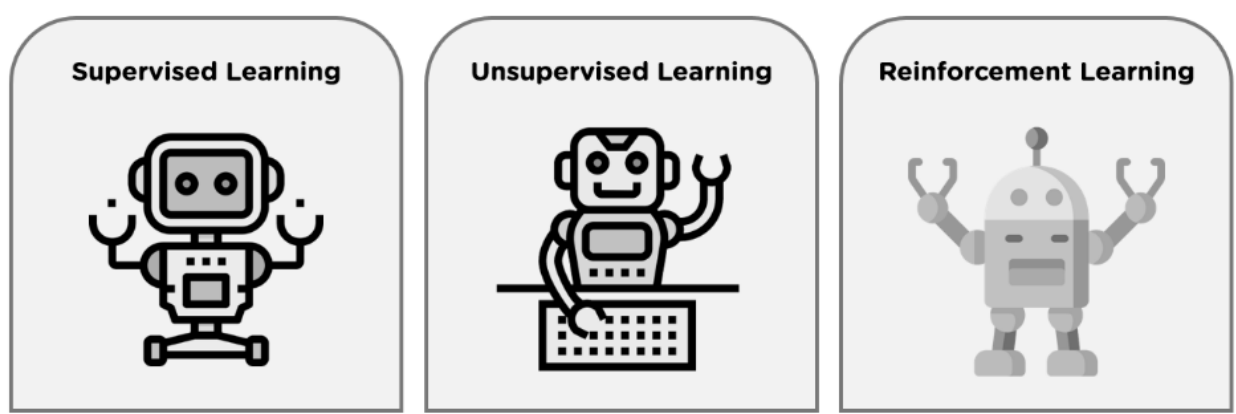

Figure 2. Types of machine learning [downloaded from Google].

Machine learning is of three types (see Figure 2). The first type is supervised learning [37], where the data consists of pairs of inputs and outputs, and the training data is categorised. Furthermore, the output data obtained as a result of the information is included in the training data as these inputs are categorized by external work. In addition, this type has many outputs, which are the outputs of binary classification for the results of a binary class. Differential learning is the name for multiclass classification, and it occurs when the outputs are limited. Still, if the outputs are of real value, this is known as regression or functional learning. Examples of this type of learning include handwriting [38], predicting stock market values, forecasting weather, and rating news in a news agency. The second type is unsupervised learning [39][40], where the data consists of inputs only, and there are no outputs. In this learning, models and structures appear in the data automatically. For illustration, suppose the task is only to separate films in a particular database by age. In that case, films with the same characteristics can be grouped with unsupervised learning, and a category can be created, and that category has no name. The third type is reinforcement learning [41]. There are no outputs for each input in the training data in this type. Instead, it gives several potential outputs of that output rather than the actual output, along with a measure of how sound that output is. This type is characterised by having a few inputs and a small number of outputs and results for these outputs. As for supervised learning, there are confirmed inputs and outputs. In addition, reinforcement learning is helpful in learning how to play a game, such as backgammon, as it helps games decide to make the best move against several moves. In supervised learning, there is a problematic mechanism in making the decision to choose the best action. In short, reinforcement learning makes making decisions much more accessible.

\subsection{Big data}

After surveying a set of literature on the topic of big data, it can be outlined as a set of mathematical procedures enforced to transfer large amounts of data in many fields in order to extract useful information that displays certain patterns, relationships and connections related to an organisation. Bigdata is exploited in many different fields and has future trends in the coming years [42][43] and interacts with the Internet of things in a civilised and industrial environment [44]. For instance, air quality data, relative temperature and humidity, dealing with biometric systems and surveillance cameras that seek to assist health workers by studying the health status of people in a particular place using sensors and thermal cameras, as well as early identification of possible infection Through the use of biosensors and nanosensors strategically placed in the city or anywhere [45-47].In addition, big data is five defining characteristics for developing a research project: size, diversity, speed, suitability, and value. Size requires extensive data processing and storage resources represented in a set that can be structured or unstructured. As for speed, it refers to the amount of data that is represented periodically and requires advanced and modern devices and technologies. Moreover, the stored data must be correct; otherwise, valuable computational resources will be wasted on unreliable or unhelpful information, leading to incorrect results and incorrect decision-making related to suitability. As for value, it is understood as the extraction of relevant information for determining strategies and decision-making. In the time of COVID-19 [48-50], it requires making an extensive database that includes massive data to distinguish between virus families, treatments and risks and analysing this data using artificial intelligence techniques and its purpose to diagnose and treat the patient and save lives. In other words, the five characteristics must be attending, reliable, and beneficial so that artificial intelligence, deep learning, and machine learning systems can analyse them and reach correct and accurate decisions. Using big data [51-53], COVID-19 data can be analysed by predicting the spread of the virus and monitoring patients, and this is what artificial intelligence techniques do [54][55].From the above, it is clear that big data is part of the statistical and mathematical techniques distinguished in the study variables that allow the expansion of techniques and models represented as groups through patterns or data correlations, which in turn can be combined with artificial intelligence to improve results. In the study of structured and unstructured databases, frequent correlations are searched to arrive at a reasonable solution that anticipates an event, such as the case of COVID-19. That is, it can be determined the spread of the virus in a particular area under climatic parameters, demographic density factors, mobility patterns, and phenotypic characteristics of the virus in relation to its other family and environment. In short, big data uses artificial intelligence techniques found in machine learning and deep learning to analyse it and reach a correct and reasonable decision. 


\section{CONCLUSIONS}

Artificial intelligence is one of the most progressive sciences at the present time, and it is expected that this development will grow more and more in the future. Today, it has a significant role in many areas, multiple tasks, speed in completing tasks and assisting in making decisions. The critical question is, is there an unethical role for artificial intelligence, or in other words, does moral responsibility fall on the machine or the human being for the errors committed by the machines?. In other words, it likes to build artificial intelligence systems correctly and not use them in unethical ways because this science is intended to help humans complete their work and not against them. Therefore, it is necessary to evaluate $\mathrm{AI}$ as an ethical component and establish international ethical rules.

\section{REFERENCES}

[1] Thiebes S., Lins S., and Sunyaev A., “Trustworthy artificial intelligence,"Electronic Markets, vol.31, pp:447-464, October 2020. https://doi.org/10.1007/s12525-020-00441-4

[2] Gunasekeran D. V., Tseng R. M. W., Tham Y., and Wong T. Y., "Applications of digital health for public health responses to COVID-19: a systematic scoping review of artificial intelligence, telehealth and related technologies,"npj Digital Medicine, vol. 4, Article number: 40, pp:1-6, February 2021. https://doi.org/10.1038/s41746-021-00412-9

[3] Pan Y. and Zhang L., "Roles of artificial intelligence in construction engineering and management: A critical review and future trends,"Automation in Construction, vol. 122, pp:103517, February 2021. https://doi.org/10.1016/j.autcon.2020.103517

[4] Mallikarjuna A., "Impact of Artificial Intelligence (AI) Applications on Academic Libraries,"International Journal of Information, Library \& Society, vol.9, no.1, pp:12-16, 2020.

[5] Tang A., Tam R., Cadrin-Chênevert A., Guest W., , Chong J., Barfett J., et al., "Canadian Association of Radiologists White Paper on Artificial Intelligence in Radiology,"Canadian Association of Radiologists Journal, vol.69, pp:120-135, May 2018. https://doi.org/10.1016/j.carj.2018.02.002

[6] Patel V. L., Shortliffe E. H., Stefanelli M., Szolovits P., Berthold M. R., Bellazzi R., and Abu-Hanna A., "The coming of age of artificial intelligence in medicine,"Artificial Intelligence in Medicine, vol.46, no.1, pp:5-17, May 2009. https://doi.org/10.1016/j.artmed.2008.07.017

[7] Aggarwal K., Mijwil M. M., Al-Mistarehi AH., Alomari S., Gök M., Alaabdin A. M., and Abdulrhman S. H., "Has the Future Started? The Current Growth of Artificial Intelligence, Machine Learning, and Deep Learning," Iraqi Journal for Computer Science and Mathematics, vol.3, no.1, pp:115-123, January 2022.

[8] Mijwil M. M., Salem I. E, and Abttan R. A. "Utilisation of Machine Learning Techniques in Testing and Training of Different Medical Datasets," Asian Journal of Computer and Information Systems, vol.9, no.5, pp:29-34, November 2021. https://doi.org/10.24203/ajcis.v9i4.6765

[9] van der Maas H. L. J., Snoek L., and Stevenson C. E., "How much intelligence is there in artificial intelligence? A 2020 update,"Intelligence, vol. 87, pp:101548, August 2021. https://doi.org/10.1016/j.intell.2021.101548

[10]Zeadally S., Adi E., Baig Z., and Khan I. A., "Harnessing Artificial Intelligence Capabilities to Improve Cybersecurity,'IEEE Access, vol.8, pp:23817 - 23837, January 2020.https://doi.org/10.1109/ACCESS.2020.2968045

[11]Leyer M. and Schneider S., "Decision augmentation and automation with artificial intelligence: Threat or opportunity for managers?,"Business Horizons, vol.64, no. 5, pp:711-724, October 2021. https://doi.org/10.1016/j.bushor.2021.02.026

[12] Mutar D. S. M., "Computer Network Attack Detection Using Enhanced Clustering Technologies,"Asian Journal of Applied Sciences, vol.9, no.6, pp:392-396, December 2021.https://doi.org/10.24203/ajas.v9i6.6839

[13] Bennett M. T. and Maruyama Y., "Philosophical Specification of Empathetic Ethical Artificial Intelligence," IEEE Transactions on Cognitive and Developmental Systems, pp:1-1, July 2021. https://doi.org/10.1109/TCDS.2021.3099945

[14] Arslan A., Cooper C., Khan Z., Golgeci I., and Ali I., "Artificial intelligence and human workers interaction at team level: a conceptual assessment of the challenges and potential HRM strategies,"International Journal of Manpower, July 2021.

[15] Mijwil M. M., Al-Mistarehi AH., and Aggarwal K., “The Effectiveness of Utilising Modern Artificial Intelligence Techniques and Initiatives to Combat COVID-19 in South Korea: A Narrative Review," Asian Journal of Applied Sciences, vol.9, no.5, pp:343-352, November 2021. https://doi.org/10.24203/ajas.v9i5.6753

[16] Muhammad L. J. and Algehyne E. A., "Fuzzy based expert system for diagnosis of coronary artery disease in nigeria,"Health and Technology, vol.11, pp:319-329, February 2021. https://doi.org/10.1007/s12553-021-00531-z

[17] Salman F. M. and Abu-Naser S. S., "Expert System for Castor Diseases and Diagnosis," International Journal of Engineering and Information Systems (IJEAIS), vol.3, no.3, pp:1-10, March 2019.

[18] Mahmud T., Sikder J., Salma U., Naher S. R., Fardoush J., Sharmen N., and Tripura S., “An Optimal Learning Model for Training Expert System to Detect Uterine Cancer," Procedia Computer Science, vol. 184 pp: 356-363, 2021. https://doi.org/10.1016/j.procs.2021.03.045 
[19] Mijwil M. M., and Abttan R. A., "Artificial Intelligence: A Survey on Evolution and Future Trends," Asian Journal of Applied Sciences, vol.9, no.2, pp:87-93, April 2021, https://doi.org/10.24203/ajas.v9i2.6589

[20] Kartika D., Gema R. L., and Pratiwi M., "Identifying Severe Malnutrition in Children with an Expert System,"Journal of Computer Science and Information Technology, vol.7, no.2, pp:15-20. https://doi.org/10.35134/jcsitech.v7i2.3

[21] Pawan E., Thamrin R. M. H., Widodo W., Bei S. H. Y., Luanmasa J. J., "Implementation of Forward Chaining Method in Expert System to Detect Diseases in Corn Plants in Muara Tami District,"International Journal of Computer and Information System, vol.3, no.1, pp:27-33, February 2022.

[22] Mufadhol M., Hartono B., Sulartopo S., Dewi M. U., Danang D., Aryotejo G., "The calculation of point quantity for lighting based on android OS using ionic framework and rule based expert system," Bulletin of Electrical Engineering and Informatics, vol.10, no.6, pp:3444-3451, December 2021. https://doi.org/10.11591/eei.v10i6.3183

[23] Straub J., Machine learning performance validation and training using a 'perfect' expert system, MethodsX, vol.8, pp:101477, 2021. https://doi.org/10.1016/j.mex.2021.101477

[24] Lareyre F., Adam C., Carrier M., and Raffort J., "Automated Segmentation of the Human Abdominal Vascular System Using a Hybrid Approach Combining Expert System and Supervised Deep Learning,"Journal of Clinical Medicine, vol.10, no.15, July 2021. https://doi.org/10.3390/jcm10153347

[25] Gupta S., Bhardwaj A., Mahawar A., and Gupta S., "A Case Study of Artificial Intelligence is being used to Reshape Business," International Journal of Electrical, Electronics and Computers, vol.6, no.3, June 2021.

[26] Yu G., Chen Z., Wu J., and Tan Y., "Medical decision support system for cancer treatment in precision medicine in developing countries," Expert Systems with Applications, vol.186, pp:115725, December 2021. https://doi.org/10.1016/j.eswa.2021.115725

[27] Azad M. M., Ganapathy A., Vadlamudi S., Paruchuri H., "Medical Diagnosis using Deep Learning Techniques: A Research Survey,"Annals of the Romanian Society for Cell Biology, vol.25, no.6, pp:5591-5600, May 2021.

[28] Bowling M., Fürnkranz J., Graepel T., and Musick R., "Machine learning and games," Machine Learning, vol. 63, pp:211-215, May 2006. https://doi.org/10.1007/s10994-006-8919-x

[29] Mijwil M. M., "Implementation of Machine Learning Techniques for the Classification of Lung X-Ray Images Used to Detect COVID-19 in Humans," Iraqi Journal of Science, vol.62, no.6., pp: 2099-2109, July 2021. https://doi.org/10.24996/ijs.2021.62.6.35.

[30] Iqbal M J, Javed Z, Sadia H, Qureshi I. A., Irshad A, Ahmed R, et al., "Clinical applications of artificial intelligence and machine learning in cancer diagnosis: looking into the future," Cancer Cell International, vol.21, Article number: 270, pp:1-11, May 2021. https://doi.org/10.1186/s12935-021-01981-1

[31] Mijwil M. M., "Malware Detection in Android OS Using Machine Learning Techniques," Data Science and Applications, vol.3, no.2, pp:5-9, December 2020.

[32] Mohan S., Thirumalai C., and Srivastava G., "Effective Heart Disease Prediction Using Hybrid Machine Learning Techniques,"IEEE Access, vol.7, pp:81542 - 81554, June 2019. https://doi.org/10.1109/ACCESS.2019.2923707

[33] Mijwil M. M. and Al-Zubaidi E. A., "Medical Image Classification for Coronavirus Disease (COVID-19) Using Convolutional Neural Networks," Iraqi Journal of Science, vol.62, no.8, pp: 2740-2747, August 2021. https://doi.org/10.24996/ijs.2021.62.8.27.

[34] Mijwil M. M. and Salem I. E., "Credit Card Fraud Detection in Payment Using Machine Learning Classifiers," Asian Journal of Computer and Information Systems, vol.8, no.4, pp:50-53, December 2020, https://doi.org/10.24203/ajcis.v8i4.6449

[35] Shah D., Patel S., and Bharti S. K., "Heart Disease Prediction using Machine Learning Techniques,"SN Computer Science, vol. 1, Article number: 345, October 2020. https://doi.org/10.1007/s42979-020-00365-y

[36] Xu C. and Jackson S. A., "Machine learning and complex biological data,"Genome Biology, vol. 20, Article number: 76, April 2019. https://doi.org/10.1186/s13059-019-1689-0

[37] Engelen J. E. and Hoos H. H., “A survey on semi-supervised learning,"Machine Learning, vol.109, pp:373-440, November 2019. https://doi.org/10.1007/s10994-019-05855-6

[38] Al-Zubaidi E. A., Mijwil M. M., and Alsaadi A. S., "Two-Dimensional Optical Character Recognition of Mouse Drawn in Turkish Capital Letters Using Multi-Layer Perceptron Classification,” Journal of Southwest Jiaotong University, vol.54, no.4, pp.1-6, Augusts 2019, https://doi.org/10.35741/issn.0258-2724.54.4.4.

[39] Chen C., Juan H., Tsai M., and Lu H. H., Unsupervised Learning and Pattern Recognition of Biological Data Structures with Density Functional Theory and Machine Learning, Scientific Reports, vol. 8, Article number: 557, January 2018. https://doi.org/10.1038/s41598-017-18931-5

[40] Sinaga K. P. and Yang M., “Unsupervised K-Means Clustering Algorithm,’IEEE Access, vol.8, pp: 80716 - 80727, April 2020. https://doi.org/10.1109/ACCESS.2020.2988796

[41] Anh T. T., Luong N. C., Niyato D., Kim D. I., and Wang L., "Efficient Training Management for Mobile CrowdMachine Learning: A Deep Reinforcement Learning Approach,"IEEE Wireless Communications Letters, vol.8, no.5, pp:1345 - 1348, october 2019. https://doi.org/10.1109/LWC.2019.2917133

[42] Mijwil M. M. and Abttan R. A., "Utilizing the Genetic Algorithm to Pruning the C4.5 Decision Tree Algorithm," Asian Journal of Applied Sciences, vol.9, no.1, pp:45-52, February 2021, https://doi.org/10.24203/ajas.v9i1.6503 
[43] Kersting K. and Meyer U., "From Big Data to Big Artificial Intelligence?,"KI - KünstlicheIntelligenz, vol. 32, pp:38, January 2018. https://doi.org/10.1007/s13218-017-0523-7

[44] Aggarwal K., Bhamrah M.S. and Ryait H.S., "Detection of cirrhosis through ultrasound imaging by intensity difference technique", Eurasip Journal on Image and Video Processing, vol 80, issue-1, 1-10, 2019. https://doi.org/10.1186/s13640-019-0482-Z

[45] Aggarwal K., Bhamrah M.S. and Ryait H.S.,"The Identification of Liver Cirrhosis with Modified LBP Grayscaling and Otsu Binarisation", Springer Plus, vol. 5, issue-1, pp.1-15, 2016.

[46] Greaves R. F., Bernardini S., Ferrari M., Fortina P., Gouget B., Gruson D., et al., "Key questions about the future of laboratory medicine in the next decade of the 21st century: A report from the IFCC-Emerging Technologies Division," Clinica Chimica Acta, vol.495, pp:570-589, August 2019. https://doi.org/10.1016/j.cca.2019.05.021

[47] Fritea K., Banica F., Costea T. O., Moldovan L., Dobjanschi L., Muresan M., and Cavalu S., "Metal Nanoparticles and Carbon-Based Nanomaterials for Improved Performances of Electrochemical (Bio)Sensors with Biomedical Applications," Materials, vol.14, no.21, pp:1-37, October 2021. https://doi.org/10.3390/ma14216319

[48] Mijwil M. M., Alsaadi A. S, and Aggarwal K., "Differences and Similarities Between Coronaviruses: A Comparative Review," Asian Journal of Pharmacy, Nursing and Medical Sciences, vol.9, no.4, pp:49-61, September 2021. https://doi.org/10.24203/ajpnms.v9i4.6696

[49] Sekeroglu B. and Ozsahin I., "Detection of COVID-19 from Chest X-Ray Images Using Convolutional Neural Networks," SLAS Technology, vol.25, no.6, pp:553-565, September 2020. https://doi.org/10.1177/2472630320958376

[50] Polat Ç., Karaman O., Karaman C., Korkmaz G., Balcı M. C., and Kelek S. E., "COVID-19 diagnosis from chest Xray images using transfer learning: Enhanced performance by debiasing dataloader," Journal of X-Ray Science and Technology, vol.29, no.1, pp:19-36, February 2021. https://doi.org/10.3233/XST-200757

[51] Ali A. H., Abdullah M. Z., Abdul-wahab S. N., and Alsajri M., "A Brief Review of Big Data Analytics Based on Machine Learning," Iraqi Journal For Computer Science and Mathematics, vol. 1, no. 2, pp. 13-15, Jul. 2020.

[52] Ali A. H., Hussain Z. F., and Abd S. N., "Big Data Classification Efficiency Based on Linear Discriminant Analysis," Iraqi Journal For Computer Science and Mathematics, vol. 1, no. 1, pp. 7-12, Jan. 2020.

[53] Haleem A., Javaid M., Khan I. H., and Vaishya R., Significant Applications of Big Data in COVID-19 Pandemic, Indian Journal of Orthopaedics, vol. 54, pp:526-528, May 2020. https://doi.org/10.1007/s43465-020-00129-Z

[54] Wang C. J., Ng C. N., and Brook R. H., "Response to COVID-19 in Taiwan Big Data Analytics, New Technology, and Proactive Testing," JAMA, vol. 323, no.14, pp:1341-1342. https://doi.org/10.1001/jama.2020.3151

[55] Hussain A. A., Bouachir O., Al-Turjman F., and Aloqaily M., "Notice of Retraction: AI Techniques for COVID-19," IEEE Access, vol. 8, pp:128776 -128795, July 2020. https://doi.org/10.1109/ACCESS.2020.3007939 